\title{
Rancang Bangun FM Transmitter Dengan Metode Spread Spectrum Signal Berbasis Raspberry Pi
}

\author{
Achmad Hanif ${ }^{1}$, Aad Hariyadi ${ }^{2}$ Aisah $^{3}$ \\ ${ }^{1}$ Program Studi Jaringan Telekomunikasi Digital, \\ 2,3 Program Studi Teknik Telekomunikasi \\ Jurusan Teknik Elektro, Politeknik Negeri Malang, Indonesia \\ 1.
}

\begin{abstract}
The need for a communication system that can solve interference problems, can guarantee the confidentiality of information sent and can operate at low $\mathbf{S}$ / N (Signal to Noise Ratio) levels or is resistant to large noise. One of the technology in communication systems is the spread spectrum system An important characteristic of spread-spectrum communication is that it can provide protection against interfering signals with limited radio communication power using RDS technology and SBC-based spread spectrum which is compatible with spread spectrum technology which requires little power for operation SBC (Raspberry pi) can be implemented into an FM transmitter using the Broadcom bcm 2837 SOC socket which will produce a base clock, then the output signal will be generated via the GPIO 7.
\end{abstract}

Keywords - FM Transmitter, Raspberry, Spread Spectrum, SBC, rds.

Abstrak-Kebutuhan akan sistem Komunikasi yang dapat mengatasi masalah interferensi, dapat menjamin kerahasiaan informasi yang dikirim dan dapat beroperasi pada tingkat $\mathbf{S} / \mathbf{N}$ (Signal to Noise Ratio) yang rendah atau tahan terhadap pada derau yang besar.Salah tekonologi dalam sistem komunikasi adalah sistem spread spectrum. karakteristik penting dari komunikasi spread-spectrum adalah bahwa dapat memberikan perlindungan terhadap sinyal yang mengganggu dengan daya yang terbatas. SBC (Raspberry pi) dapat diimplementasikan menjadi sebuah pemancar FM dengan menggunakan socket SOC Broadcom bcm 2837 yang akan menghasilkan sebuah base clock, kemudian sinyal output akan dihasilkan melalui pin GPIO 7.

Kata kunci- FM Transmitter, Raspberry, Spread Spectrum, SBC, rds.

\section{PENDAHULUAN}

Kebutuhan akan sistem komunikasi yang dapat mengatasi masalah interferensi, dapat menjamin kerahasiaan informasi yang dikirim dan dapat beroperasi pada tingkat S/N (Signal to Noise Ratio) yang rendah atau tahan terhadap pada derau yang besar. Dalam sistem komunikasi sekarang ini, dimana penggunaan frekuensi sudah cukup padat sehingga interferensi dan noise dari transceiver lain cukup besar [1].

Salah satu teknologi dalam sistem komunikasi adalah sistem spread spectrum. Karakteristik penting dari komunikasi spread-spectrum adalah bahwa dapat memberikan perlindungan terhadap sinyal yang mengganggu dengan daya yang terbatas [2].

Teknologi RDS adalah teknologi radio yang dapat mengirimkan informasi suara dan teks berjalan yang akan dikirimkan melalui gelombang radio [3]. Dengan adanya teknologi RDS maka akan dirancang sebuah sistem informasi dengan membuat alat pengirim informasi radio berbasis mikrokontroller yang informasinya berupa suara dan teks [4].

\section{METODE}

A. Pemodelan Sistem

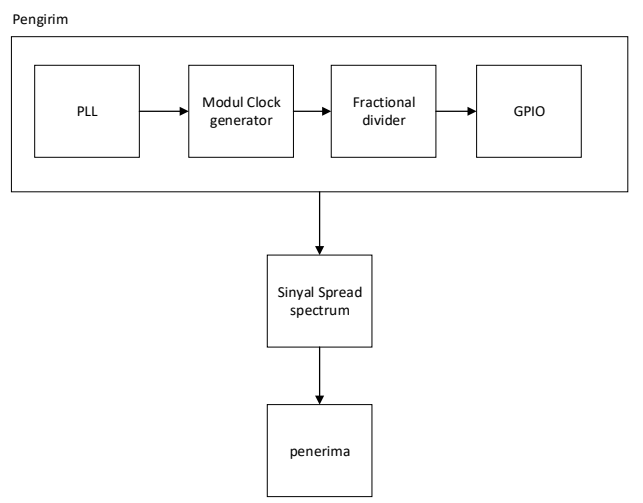

Gambar 1. Blok Diagram Perancangan Sistem 


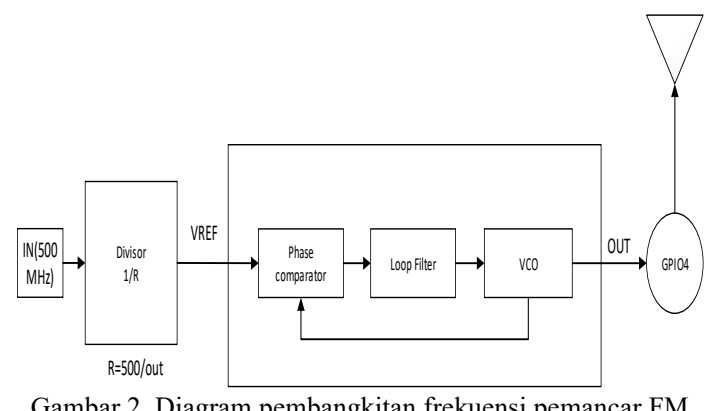

Gambar 2. Diagram pembangkitan frekuensi pemancar FM

Gambar 2 menunjukkan perancangan proses kerja kesuluruhan sistem bagaimana pada blok pengirim yaitu sebuah SBC Raspberry pi B 3+ terdapat hardware berupa clock generator module yang berperan sebagai pembangkit clock yang akan digunakan sebagai frekuensi [5]. Sumber dari clock yang akan digunakan tersebut berupa sebuah rangkaian phase lock loop yang ada pada chip Broadcom SOC 2837. Transmisi audio dapat dilakukan jika clock yang sudah ditentukan akan dihitung menggunakan frequency divider yang kemudian akan digunakan sebagai frekuensi output menggunakan pwm generator.

\section{B. Instalasi antena pemancar pada $S B C$}

Antena dihubungkan dengan kabel coaxial terlebih dahulu kemudian pada ujung ujung kabel coaxial dihubungkan pada GPIO4 Header yang ada pada Raspberry Pi. Pemasangan kabel koaksial dengan modul antena dapat dilihat pada gambar berikut:

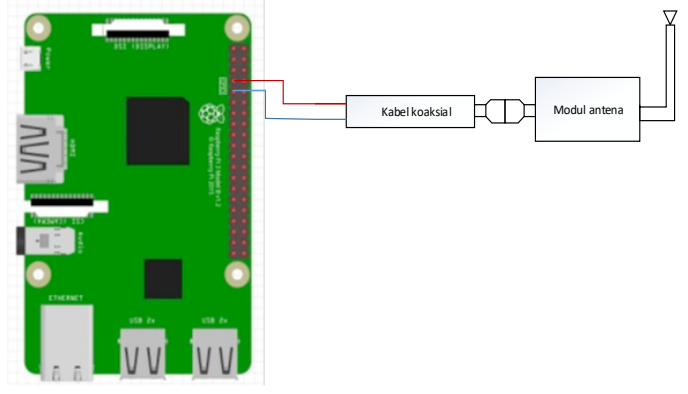

Gambar 3. Skema pengoperasian pemancar fm melalui SBC

\section{Pembangkitan Frekuensi pada SBC}

Proses pembangkitan frekuensi dilakukan pada SBC menggunakan hardware yang ada pada raspberry pi. Seperti GPIO pin dengan chip SOCBroadcom 2837 sebagai kontrolnya. Proses pembangkitan frekuensi dilakukan oleh SBC dengan menggunakan modul clock generator sebagai sumber clock dan GPIO pin 4 sebagai output.

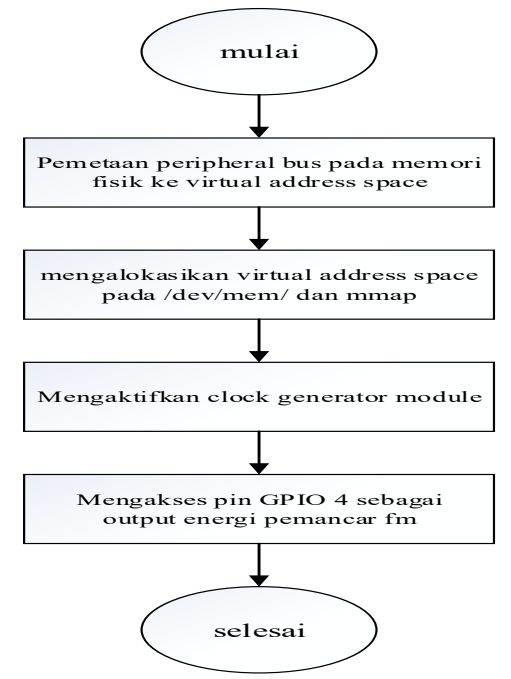

Gambar 4. Diagram Alir Pembangkitan Frekuensi pada Raspberry Pi

Program C memetakan Peripheral Bus dalam memori fisik ke ruang alamat virtual menggunakan / dev / mem dan mmap [6]. Untuk melakukan ini perlu akses root, maka memerlukan perintah sudo [8]. Selanjutnya mengatur modul clock generator untuk diaktifkan dan menetapkannya pada GPIO4 sebagai output.

\section{Konfigurasi frekuensi output}

Menggunakan rumus sebagai berikut:

Frekuensi $=300 /$ panjang antenna $/ 16 * 100$

Frekuensi $=300 / 21.42 \mathrm{~cm} / 16 * 100$

Frekuensi $=87.5 \mathrm{MHz}$

Dengan catatan panjang antena disini dapat juga berupa sebuah kabel jumper yang dimasukkan pada pin GPIO 4 dengan panjang $21.42 \mathrm{~cm}$.

\section{HASIL DAN PEMBAHASAN}

\section{A. Pembahasan SBC dapat digunakan sebagai pemancar}

Raspberry Pi memiliki sistem digital sinkron yang terkait dengannya yang digunakan untuk mengurangi interferensi elektromagnetik. Penindasan EMI ini dilakukan oleh sinyal yang disebut Spread-spectrum clock signal atau SSCS. Frekuensi sinyal ini dapat bervariasi dari $1 \mathrm{MHz}$ hingga 250 $\mathrm{MHz}$, hal ini dapat dimanfaatkan sebagai pemancar karena masuk didalam pita gelombang radio FM.Chip Broadcom bcm2873 menggunakan PLLD $500 \mathrm{MHz}$ sebagai input [8].

Sinyal termodulasi akan diberikan melalui pin 4 GPIO dari Raspberry Pi, dengan memasang kabel normal minimum $20 \mathrm{~cm}$ ke pin 4 GPIO tersebut sebagai antena. Pemancar FM ini akan bekerja dari sekitar $1 \mathrm{Mhz}$ hingga $250 \mathrm{Mhz}$.

\section{B. Perhitungan daya rata-rata pemancar}

Dengan mengingat bahwa output tegangan maksimum dari Raspberry Pi 3.3 Volt, arus maksimum GPIO adalah 16 $\mathrm{mA}$. Untuk memperhitungkan daya yang dipancarkan dapat dihitung dengan menggunakan persamaan [9] seperti berikut: 


$$
\begin{aligned}
& \text { Pavg }=\text { Vrms } x \text { Imax } \\
& \text { Vrms }=\frac{V p}{\sqrt{2}} \\
& \text { Pavg }=3,3 \cdot 0,707 \cdot 0,0001=0,37 \text { Watt }
\end{aligned}
$$

\section{Dimana:}

Pavg = Daya rata-rata,

Vrms $=$ Tegangan rms

Imax $=$ Arus Maksimal

$\mathrm{Vpp}=$ Tegangan peak-to-peak.

Pada persamaan (1) hingga (3) terlihat daya yang dihasilkan masih dalam taraf yang kurang dari $500 \mathrm{~mW}$, sehingga tidak diperlukan untuk perijinan untuk memperkuat daya pemancar FM.

\section{Hasil pengukuran parameter pemancar FM}

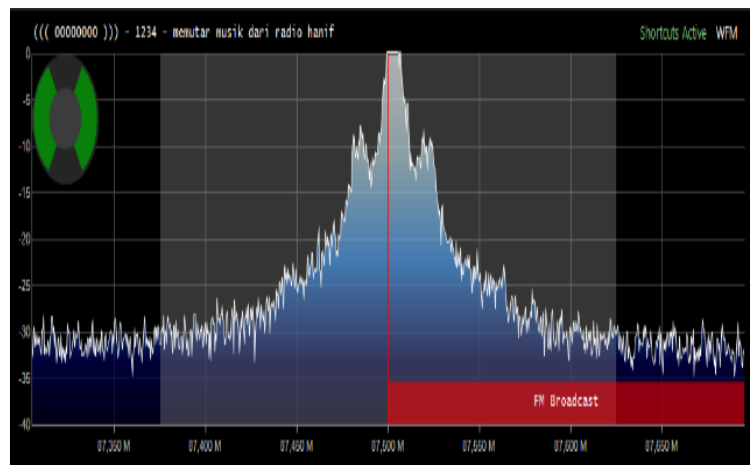

Gambar 5. Spektrum fm dari pemancar SDR

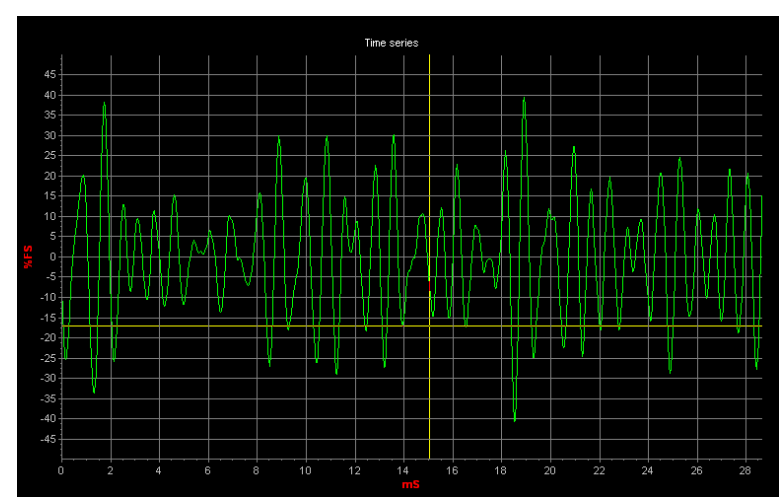

Gambar 6. Sinyal DSSS domain waktu

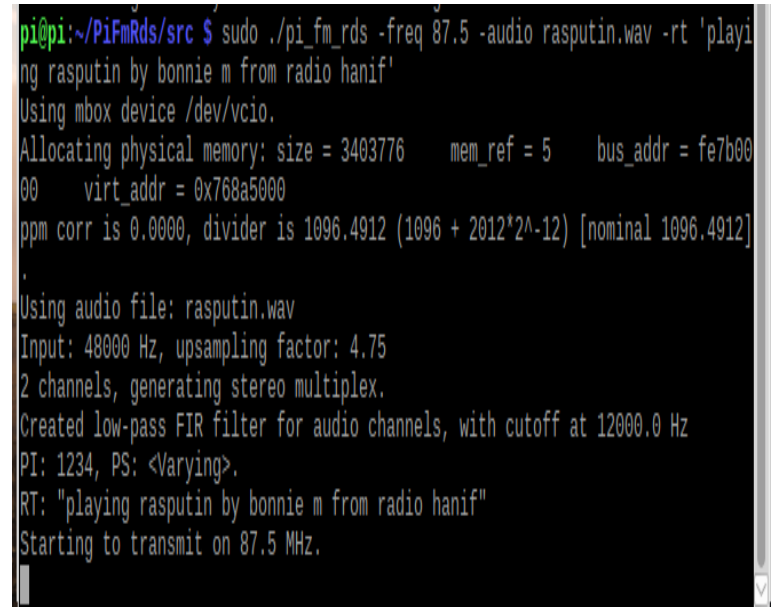

Gambar 7. Input audio

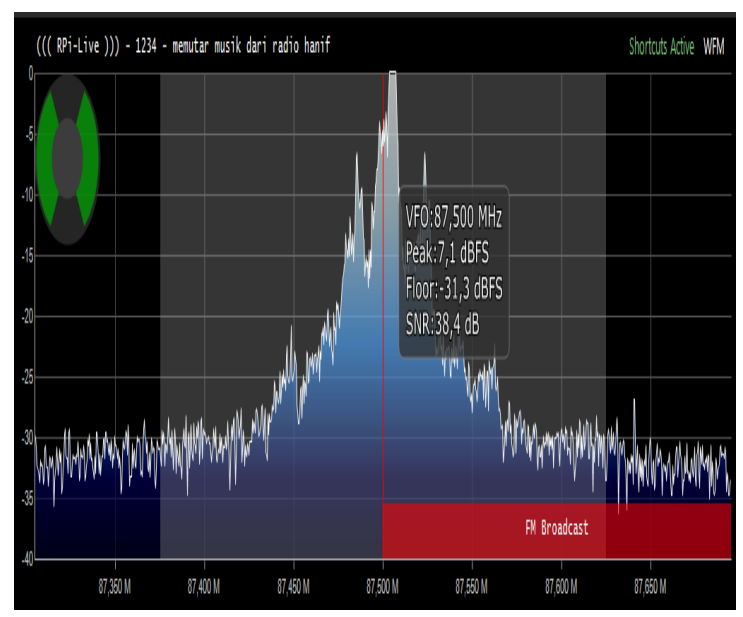

Gambar 8. Hasil scanning transmisi fm audio

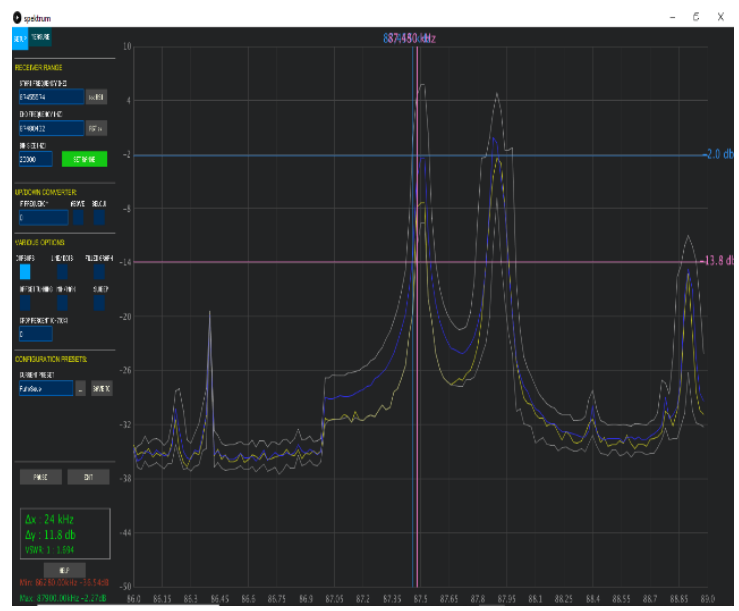

Gambar 9. Hasil pengukuran deviasi frekuensi transmisi fm

Dari hasil pengukuran di atas dapat menghasilkan perhitungan perhitungan parameter sebagai berikut:

Deviasi $(\partial)=24 \mathrm{Khz}$

Frekuensi pemodulasi $(\mathrm{fm})=48 \mathrm{Khz}$

Sehingga indeks modulasi: 


$$
m f=\frac{\partial}{f m}=\frac{24}{48}=0.5
$$

Dan bandwidth dengan aturan carson sebesar: $B W=2(\partial+\mathrm{fm})=2(24+48)=144 \mathrm{KHz}$

Nilai SNR:

$$
\begin{gathered}
S N R=\text { sinyal }- \text { noise floor }=7-(-31.3) \\
=38.3
\end{gathered}
$$

Sehingga modulasi sesaat:

$$
\begin{gathered}
e F M=e c \sin (\omega c t+m f \sin \omega m t) \\
e F M=3.3 \sin (628+0.5 \sin (0.301)) \\
e F M=-0.56 M h z
\end{gathered}
$$

\section{Perbandingan hasil pengukuran transmisi fm mono dan} stereo

TABEL I

HASIL PENGUKURAN SINYAL FM STEREO

\begin{tabular}{cc}
\hline Nama parameter & Satuan \\
\hline VFO (center frequency) & $87.5 \mathrm{MHz}$ \\
Level (peak) & $7 \mathrm{dBFS}$ \\
Noise floor & $-31.3 \mathrm{dBFS}$ \\
Signal to noise ratio (SNR) & $38.3 \mathrm{~dB}$ \\
Deviasi frekuensi & $24 \mathrm{Khz}$ \\
Frekuensi pemodulasi & $48 \mathrm{Khz}$ \\
Indeks modulasi & 0.5 \\
Bandwidth & $144 \mathrm{Khz}$ \\
Frekuensi cutoff filter & $12 \mathrm{Khz}$ \\
\hline
\end{tabular}

TABEL II

HASIL PENGUKURAN SINYAL FM MONO

\begin{tabular}{cc}
\hline Nama parameter & Satuan \\
\hline VFO (center frequency) & $87.5 \mathrm{MHz}$ \\
Level (peak) & $12.5 \mathrm{dBFS}$ \\
Noise floor & $-31.2 \mathrm{dBFS}$ \\
Signal to noise ratio (SNR) & $43.7 \mathrm{~dB}$ \\
Deviasi frekuensi & $24 \mathrm{Khz}$ \\
Indeks modulasi & 1.08 \\
bandwidth & $92.1 \mathrm{Khz}$ \\
Frekuensi pemodulasi & $22.05 \mathrm{Khz}$ \\
Frekuensi cutoff filter & $8.82 \mathrm{Khz}$ \\
\hline
\end{tabular}

\section{KESIMPULAN}

Setelah melakukan perancangan dan pengujian sistem informasi pada proyek akhir ini, dapat diambil beberapa kesimpulan yaitu:

1. $S B C$ (Raspberry pi) dapat diimplementasikan menjadi sebuah pemancar FM dengan menggunakan socket SOC Broadcom bcm 2837 yang akan menghasilkan sebuah base clock yang akan digunakan sebagai sinyal carrier. kemudian sinyal output akan dihasilkan melalui pin GPIO 7 yang ada pada SBC

2. Sinyal spread spectrum yang dihasilkan oleh pemancar SBC merupakan sinyal Direct sequence spread spectrum (DSSS) dan bertipe wideband FM, namun dengan nilai bandwidth yang cukup rendah, sehingga dapat diakatakan sinyal fm masih dapat terkena interfensi elekromagnetik dan jamming.

3. Dari analisis dan perhitungan dari parameter-parameter pemancar SBC dengan tipe audio stereo dan mono didapatkan nilai yang berbeda untuk tiap parameter. Hal tersebut diakibatkan karena adanya perbedaan nilai frekuensi pemodulasi untuk audio mono dan stereo yang berbeda.

\section{REFERENSI}

[1] D. S., E. M. S. Ignatius Yoslan Kurniawan, "Perancangan Dan Implementasi Alat Pengirim Informasi Radio Menggunakan Mikrokontroler Dan Rds" Fakultas Ilmu Terapan, Universitas Telkom, 2018.

[2] dini novarianti, "Design and Implementation of Chebyshev Band Pass Filter with M-Derived Section in Frequency Band 88 - 108 MHz", Jurnal Jartel, vol. 8, no. 1, pp. 7-11, Mar. 2019.

[3] B. M. Dietmar Kopitz, "RDS: The Radio System," in RDS: The Radio System, Boston, Artech, 1999.

[4] J. Kelly, "Introduction to FMStereo-RDS," US: Verigy, 2010.

[5] S. W. Matt Richardson, Getting Started With Raspberry Pi, New York: O’Reilly Media, Inc., 2012.

[6] R. H. Yoga Perdana, N. Hidayati, A. W. Yulianto, V. Al Hadid Firdaus, N. N. Sari and D. Suprianto, "Jig Detection Using Scanning Method Base On Internet Of Things For Smart Learning Factory," 2020 IEEE International IOT, Electronics and Mechatronics Conference (IEMTRONICS), 2020, pp. 1-5.

[7] Upton, Programming the Raspberry Pi, US: Element14.com, 2012.

[8] M. Mark, Advance Linux Programming, USA: New Riders Publishing, 2001.

[9] Pangera, "Perbandingan FHSS dan DSSS" Jurnal STMIK AMIKOM Yogyakarta, 2012. 